\title{
Performances of interleaved and Face to Face integrated magnetic transformers
}

\author{
K. Youssouf ${ }^{1}$, F. Kahlouche ${ }^{1}$, M. Youssouf ${ }^{2}$, S. Capraro ${ }^{1}$, J.P. Chatelon ${ }^{1}$, A. Siblini ${ }^{1}$, J.J. Rousseau ${ }^{1}$ \\ ${ }^{1}$ Université de Lyon, F-42023, Saint Etienne, France; Université de Saint Etienne, Jean Monnet, F-42023, Saint Etienne, \\ France; LT2C, F-42023, Saint Etienne, France \\ ${ }^{2}$ IUSTA - Abéché, TCHAD
}

\begin{abstract}
Currently, most of integrated transformers are fabricated without magnetic core. In order to reduce the size and to improve their performances, we were interested in the study of integrated transformers based of thin ferrite films. Interleaved and Face to Face structures were simulated using the Ansoft HFSS simulator over a wide range of frequency (up to $100 \mathrm{MHz}$ ). A high frequency electrical model has been defined to determine the main characteristics of the transformer and particularly the inter-winding capacitance and coupling factor between primary and secondary windings. The simulation results allowed us to determine the geometrical dimensions of these structures in order to optimize the magnetic coupling coefficient and to minimize interwinding capacitance.
\end{abstract}

\section{Introduction}

The development of portable or embarked systems has seen a major expansion the last twenty years. Especially in the field of telephony, consumption computer equipment such as tablet computers, game consoles, health auxiliaries ... In the transport area the electromagnetic actuators attempt to replace mechanical actuators (hydraulic, pneumatic ...), all-electric aircraft is a main subject studied.

Weight and volume are a major constraint of specifications; the energy consumption has also to be as low as possible. To answer these compactness constraints, the increase of the operating temperature and the integration is a solution but requires the development of new materials, new electronic components. Research efforts cover all aspects: materials, components, actuators and systems.

In the field of power electronics, it is suitable to get closer converters and actuators, to increase the power density, enhance system integration. Our work fits into this approach and concerns the development of magnetic passive components for the control of converters.

The DC sources, especially converters, switching power supplies, require the use of a micro-transformer which is an element mainly used for galvanic isolation between power and control parts. Most planar microtransformers are without magnetic material [1-6].

Structures of micro-transformers operating at $200^{\circ} \mathrm{C}$ are proposed and used for applications such as DC/DC converters, driver IC or signal transmission. These microtransformers use magnetic materials that improve the increasing of the magnetizing inductance and coupling coefficient between windings. These magnetic materials behave also as a magnetic shielding. Two structures of micro- transformers (interleaved and Face to Face) were studied using a 3D full-wave electromagnetic field simulator based on finite element method (HFSS). A comparative study based on the coupling factor $\mathrm{k}$, and magnetizing inductance $\mathrm{L}_{\mathrm{F}}$, of these two structures was performed.

\section{Approach}

A lot of models transformers are developed from ideal model to models taking into account all phenomena [711]. The following model presented in this paper is showed in figure 1. This model takes into account the Joule effect losses in the primary and the secondary windings, the magnetizing inductance and the main coupling capacitance (between turns and between primary and secondary windings). Power losses (hysteresis and Eddy current losses) in the magnetic material are not taken into account due to the low operating frequencies studied $(<100 \mathrm{MHz})$.

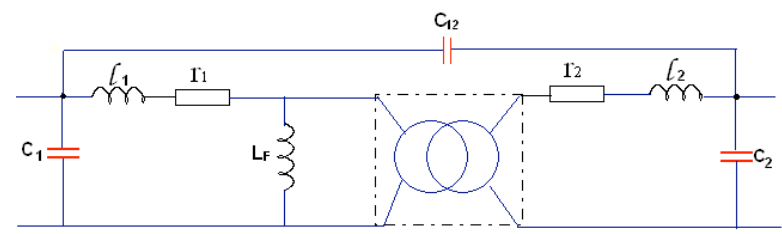

Fig. 1. HF model of the integrated transformer

This is an Open Access article distributed under the terms of the Creative Commons Attribution License 2.0, which permits unrestricted use, distribution, and reproduction in any medium, provided the original work is properly cited. 
$\mathrm{L}_{\mathrm{F}}, l_{l}$ and $l_{2}$ are the magnetizing inductance, the leakage inductance of primary and secondary respectively;

$r_{1}$ and $r_{2}$ are the resistances of the primary and secondary windings respectively;

$\mathrm{C}_{12}, \mathrm{C}_{1}$ and $\mathrm{C}_{2}$ are the capacitances between the primary and the secondary windings, between turns of the primary coil and between the secondary coil respectively.

The impedance matrix $\left(Z_{i j}\right)$ of the model has been calculated in order to determine the magnetizing inductance $\left(\mathrm{L}_{\mathrm{F}}\right)$ and the coupling capacitance $(\mathrm{k})$ which are equal to:

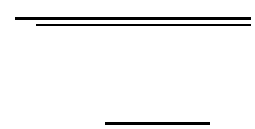

\section{Structure descriptions}

Two transformers structures have been studied: interleaved structure and 3D structure (Face to Face orientation).

\subsection{Interleaved structure}

The interleaved structure is constituted by a primary and a secondary winding where each winding is composed by the same number of turns $\left(\mathrm{N}_{1}=\mathrm{N}_{2}=10\right)$ interleaved and covered with a resin layer in order to isolate the two windings. These two windings are sandwiched between two Yttrium Iron Garnet (YIG) layers (figure 1).

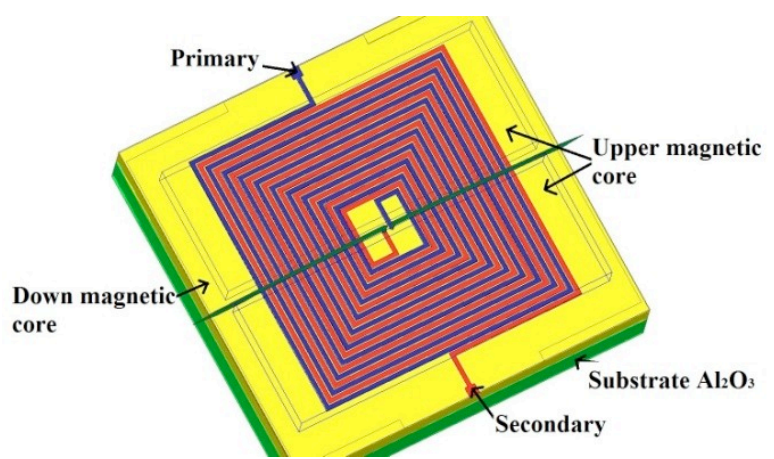

(a)

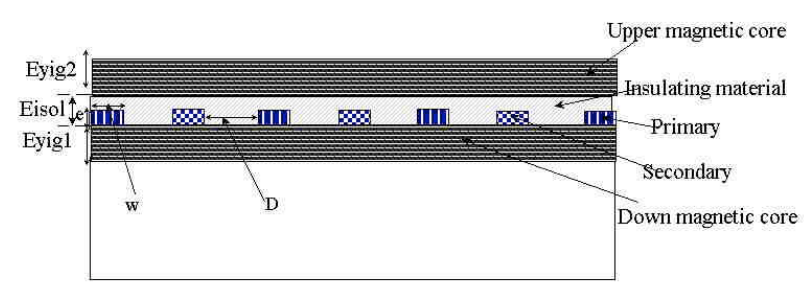

(b)

Fig. 2. Interleaved transformer design (a) $3 \mathrm{D}$ view (b) Cross section

Characteristics sizes of the interleaved structure are as follows: coil width $\mathrm{W}=60 \mu \mathrm{m}$, distance between primary and secondary coils $\mathrm{D}=100 \mu \mathrm{m}$, conductor thickness $\mathrm{e}=5 \mu \mathrm{m}$, thicknesses of down and upper magnetic layers Eyig $_{1}=$ Eyig $_{2}=100 \mu \mathrm{m}$, and resin thickness Eres $=40 \mu \mathrm{m}$.

\subsection{Face to Face transformer structure}

The Face to Face transformer structure is defined by both windings (primary and secondary coils) deposited on YIG layer and placed one on the other one, and separated by an insulating layer (figure 3 ).

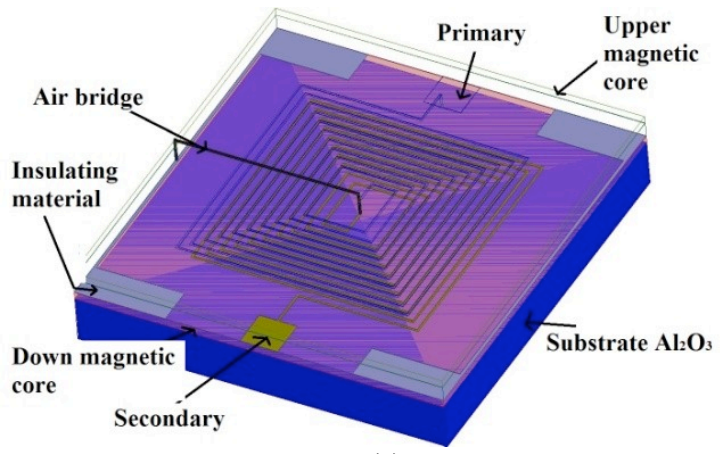

(a)

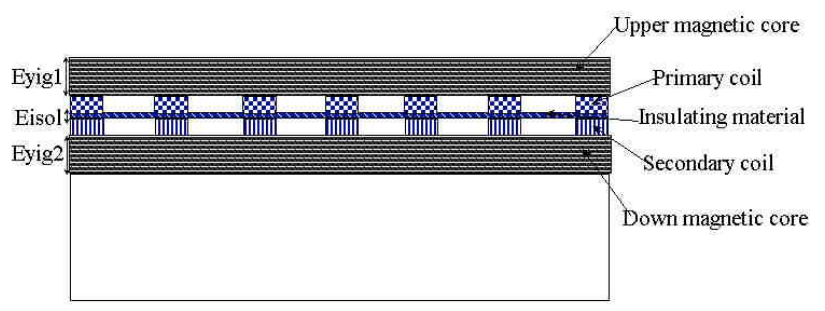

(b)

Fig. 3. Face to Face transformer design

(a) 3D view (b) Cross section

The main geometrical dimensions of this structure are as follows: coil width $\mathrm{W}=60 \mu \mathrm{m}$, distance between coil $\mathrm{D}=100 \mu \mathrm{m}$, conductor thickness $\mathrm{e}=5 \mu \mathrm{m}$ thicknesses of down and upper magnetic layers Eyig $_{1}=$ Eyig $_{2}=100 \mu \mathrm{m}$, insulating thickness Eisol $=10 \mu \mathrm{m}$.

\section{Results}

Simulations are realized using the following YIG properties: $\varepsilon_{\mathrm{r}}=15$ and $\mu_{\mathrm{r}}=25$. These properties have been kept constant because the magnetic material can be considered as ideal on this frequency band.

\subsection{Interleaved structure}

In order to study the influence of the ferrite films on the main characteristics of the transformer, simulation have been performed and the results are shown on figure 4. According to this figure, the presence of the magnetic material increases significantly the magnetizing inductance as a ratio of 4 . This factor depends on the magnetic layer thickness, the insulator thickness and films permeability. On the other hand, magnetic material increases the coupling factor $\mathrm{k}$ of the order of $5 \%$ 
because flux leakage is reduced. The frequency response of the interleaved transformer is described by using scattering parameters: reflection $\left(\mathrm{S}_{11}\right)$ and transmission $\left(\mathrm{S}_{12}\right)$ are plotted on figure 5. Results show a good transmission between primary and secondary windings with an insertion losses less than $1 \mathrm{~dB}$ in the frequency range from 30 to $100 \mathrm{MHz}$. This result confirms the strong coupling between primary and secondary winding.

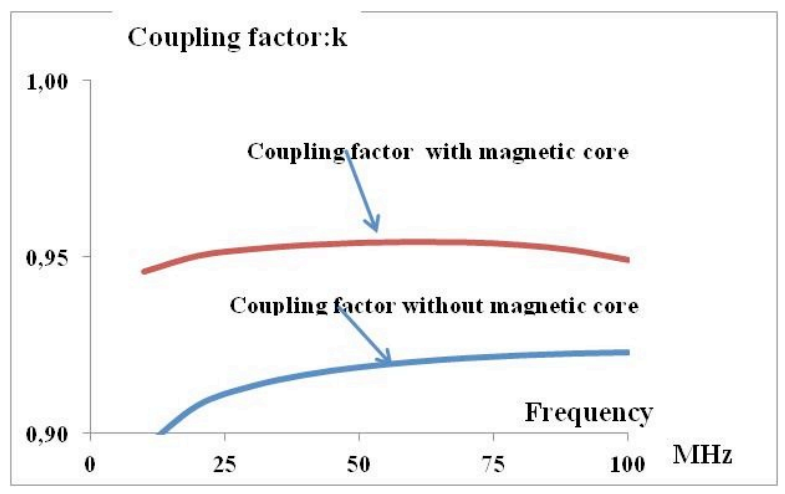

(a)

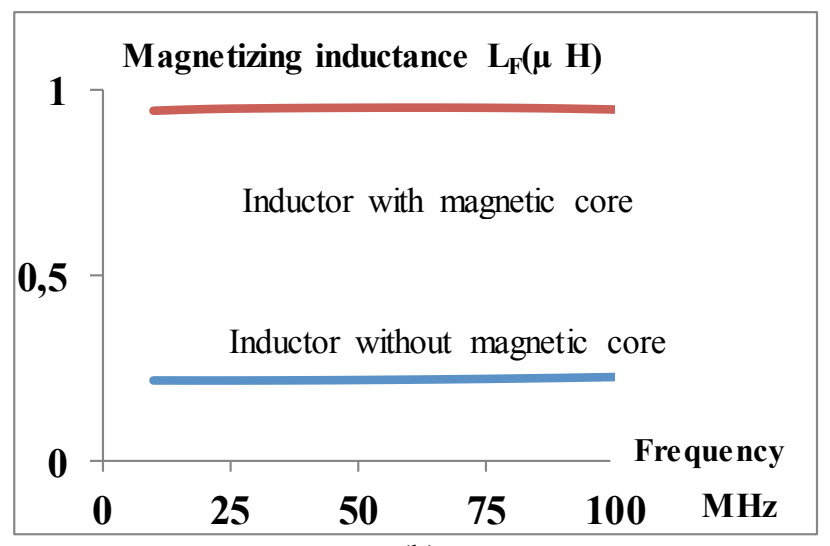

(b)

Fig. 4. Magnetic material influence on

(a) coupling factor, $\mathrm{k}(\mathrm{b})$ Magnetizing inductance, $\mathrm{L}_{\mathrm{F}}$

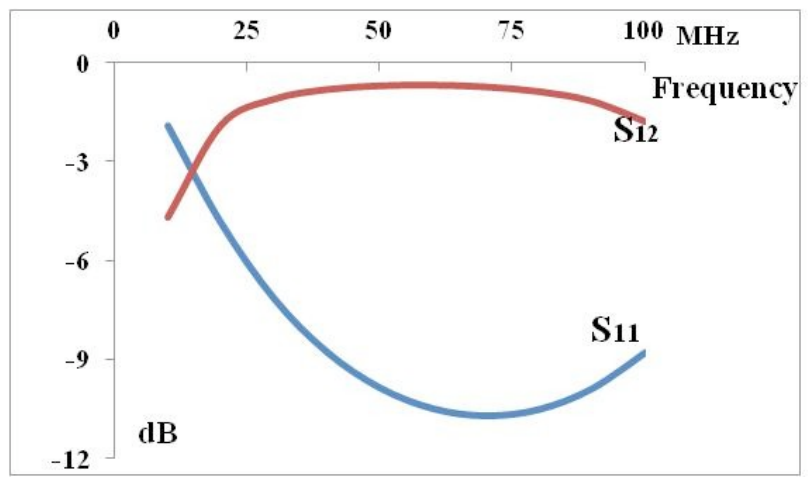

Fig. 5. $S_{12}$ and $S_{11}$ parameters of the interleaved transformer versus frequency

The main sizes values of the transformer model are resumed in Table I.
Table I. Values of the interleaved transformer

\begin{tabular}{|c|c|}
\hline $\mathrm{k}$ & 0.95 \\
\hline $\mathrm{L}_{\mathrm{F}}(\mu \mathrm{H})$ & 0.88 \\
\hline$l_{1}(\mu \mathrm{H})$ & 0.05 \\
\hline$l_{2}(\mu \mathrm{F})$ & 0.024 \\
\hline $\mathrm{r}_{1}(\Omega)$ & 6.2 \\
\hline $\mathrm{r}_{2}(\Omega)$ & 6.2 \\
\hline $\mathrm{C}_{12}(\mathrm{pF})$ & 22 \\
\hline $\mathrm{C}_{2}(\mathrm{pF})$ & 1 \\
\hline $\mathrm{C}_{1}(\mathrm{pF})$ & 2 \\
\hline
\end{tabular}

The studied interleaved structure exhibits the following advantages:

- An high magnetizing inductance

- A good coupling factor $\mathrm{k}$, up to 0.95 for $100 \mu \mathrm{m}$ ferrite thickness

- Presence of a magnetic shielding

In spite of these advantages, this structure presents also some disadvantages:

- Strong capacitive coupling between coils due to the resin permittivity $\left(\varepsilon_{\mathrm{r}}=3.8\right)$ and due to the distance between coils.

\subsection{Face to Face transformer structure}

In this part, simulations are performed in order to determine the interest of using magnetic material on the coupling factor and on the magnetizing inductance (figure 6).

Results presented on figure 6 show an increasing of coupling factor by a ratio of $6 \%$ which is identical as the interleaved structure. On the other hand, the magnetizing inductance increases too but with a higher variation than the interleaved structure.

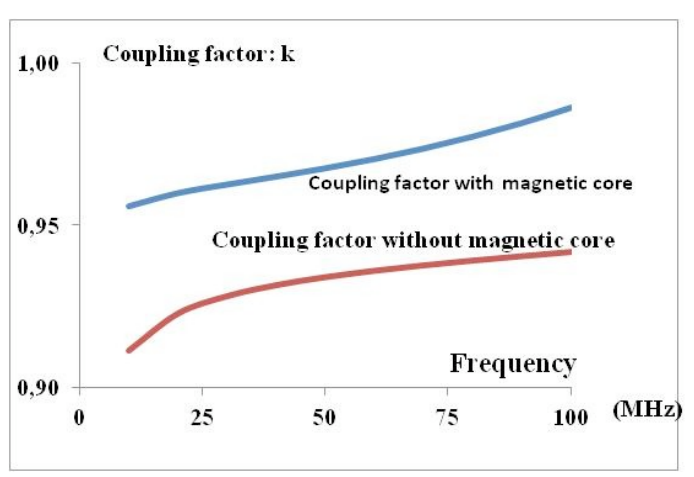

(a)

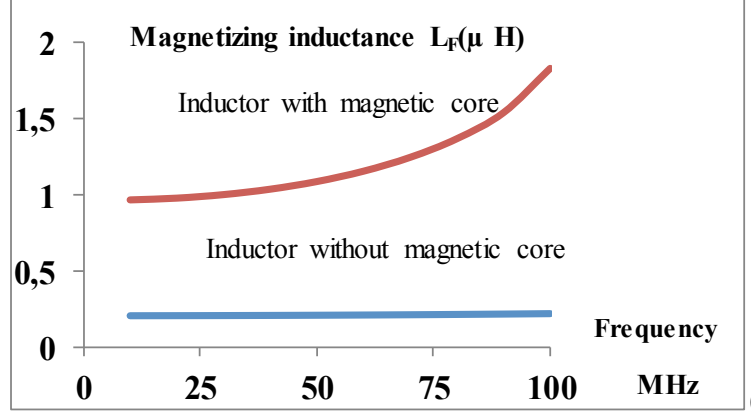

Fig. 6. Influence of the magnetic material on

(a) the coupling factor $\mathrm{k}(\mathrm{b})$ on the magnetizing inductance $\mathrm{L}_{\mathrm{F}}$ 
Figure 7 shows the reflection and transmission parameters of this transformer versus frequency. Results show a good transmission coefficient $\left(\mathrm{S}_{12}\right)$ with insertion losses less than $1 \mathrm{~dB}$ in the frequency range 30 to $100 \mathrm{MHz}$

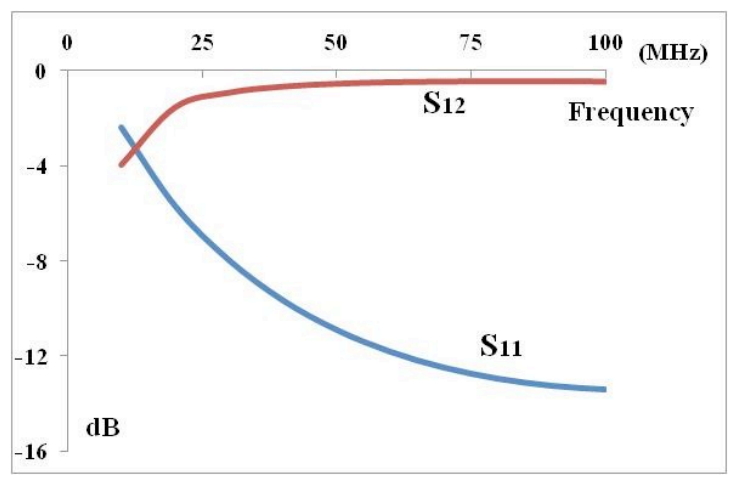

Fig. 7. $S_{12}$ and $S_{11}$ parameters of the Face to Face transformer versus frequency

The main sizes values of the Face to Face transformer model are resumed in Table II.

Table II. Values of the Face to Face transformer

\begin{tabular}{|c|c|}
\hline $\mathrm{k}$ & 0.96 \\
\hline $\mathrm{L}_{\mathrm{F}}(\mu \mathrm{H})$ & 0.96 \\
\hline$l_{1}(\mu \mathrm{H})$ & 0.055 \\
\hline$l_{2}(\mu \mathrm{F})$ & 0.03 \\
\hline $\mathrm{r}_{1}(\Omega)$ & 5.9 \\
\hline $\mathrm{r}_{2}(\Omega)$ & 5.9 \\
\hline $\mathrm{C}_{12}(\mathrm{pF})$ & 4.83 \\
\hline $\mathrm{C}_{2}(\mathrm{pF})$ & 0.58 \\
\hline $\mathrm{C}_{1}(\mathrm{pF})$ & 0.56 \\
\hline
\end{tabular}

The main advantages and disadvantages presented by this structure are summarized by the following points:

- A good coupling factor in order of 0.97

- A low capacitive coupling factor between coils

- A magnetic shielding

- Insulating material between coils increases the capacitance between primary and secondary windings due to the permittivity of this layer.

\subsection{Comparison between the two structures}

A comparative study between these two structures has been developed according to magnetizing inductance $\mathrm{L}_{\mathrm{F}}$, coupling factor $\mathrm{k}$, coupling capacitance between primary and secondary windings, technological feasibility, occupied surface and breakdown voltage.

These results are resumed in table III.

According to this study, applications where the coupling capacitance between primary and secondary windings is important, the Face to Face structure seems to be the best suitable one. On the other hand, for those where the technological feasibility is promoted, the interleaved structure will be the best candidate.
Table III. Comparison between interleaved and Face to Face transformers

\begin{tabular}{|c|c|c|}
\hline & Interleaved & Face to Face \\
\hline $\mathrm{k}$ & + & + \\
\hline $\mathrm{C}_{12}$ & + & - \\
\hline $\mathrm{L}_{\mathrm{F}}$ & + & + \\
\hline Breakdown voltage & + & + \\
\hline Realization & + & - \\
\hline Occupied surface & $=$ & $=$ \\
\hline
\end{tabular}

\section{Conclusion}

Two kinds of transformers have been studied: interleaved and Face to Face structures. Such transformers will be used for high temperature applications $\left(200^{\circ} \mathrm{C}\right)$ in the field of power electronics. A good coupling factor greater than 0.9 is usually required.

A comparative study between these two structures has been carried out. For applications which require very low interwinding capacitance, the Face to Face structure leads to better results. On the other side, interleaved transformer features an easier fabrication than Face to Face transformer. The fabrication of these two types of transformers is currently in progress and comparisons between simulation and measurement will be obtained.

\section{Acknowledgment}

This work is supported by Euripeds catrene "Thor" project.

\section{References}

1. C. Meng and al, Proc. APMC, 1 (2007)

2. C.-Z. Chen and al, Proc. RWS, 357 (2007)

3. S.M Sunderarajan. and al, Proc. IEDM, 19.3.1 (2008)

4. E. Echo and al., IEICE Trans.Electron, E93-C (1), $140(2010)$

5. C. C. Lim and al, Proc. RFIC, 167 (2008)

6. N.Shiramizu and al., Proc. SMIC ,.12 (2010)

7. D.C. Laney and al, Proc. On IEEE MTT-S, 855 (1999).

8. S. M. Azimi and al., Journal. of Multiphysics 1, 4 (2007)

9. S. Verma and J. M. Cruz, Sun Microsystems (1999)

10. S.-J. Pan and al., Journal of RF and microwave computer-aided engineering, 424 (2004)

11. C. Trask, Home.earthlink.net (2008) 